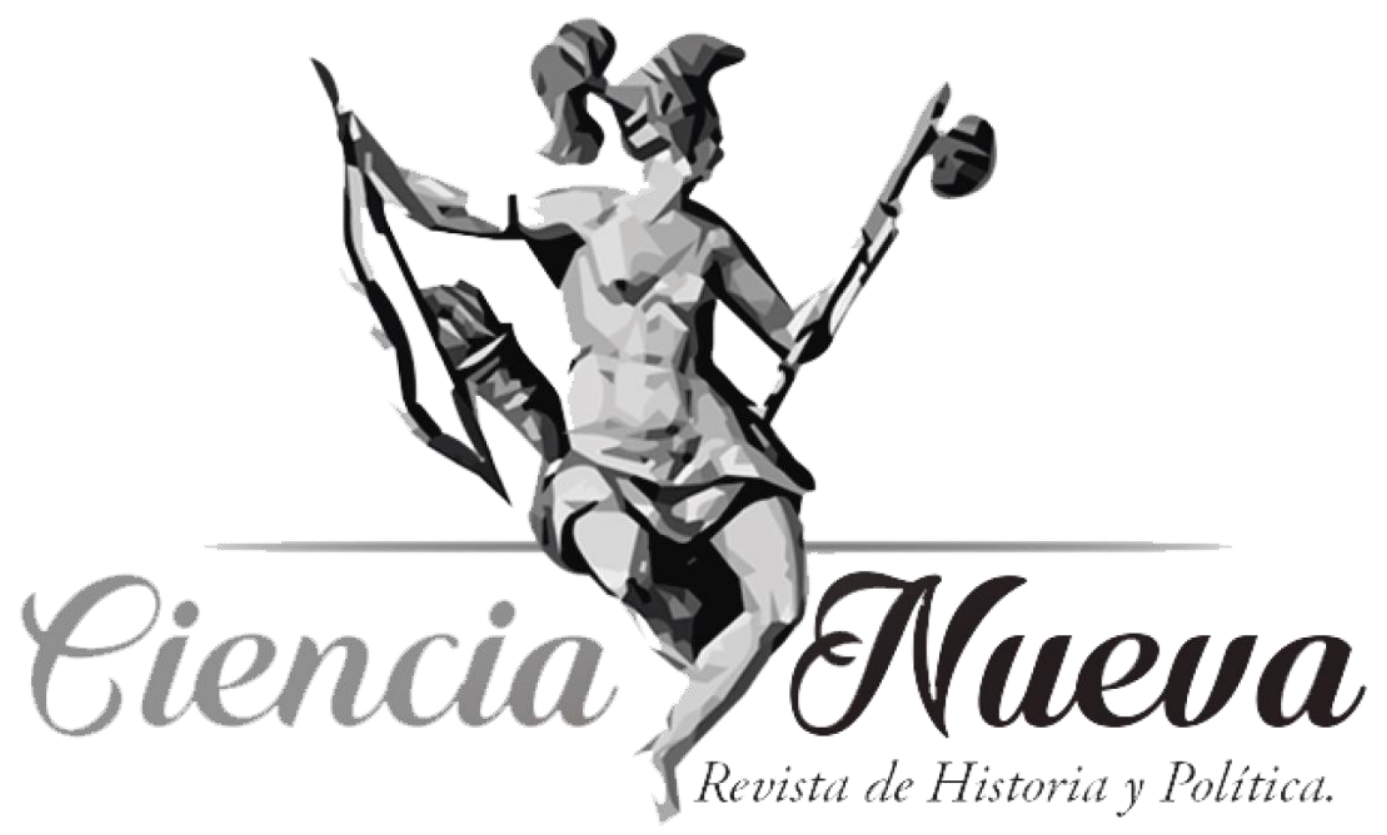

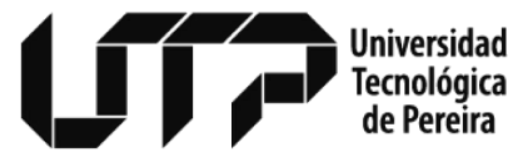

Maestría en Historia

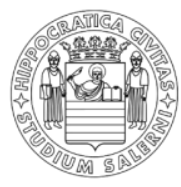

UNIVERSITÀ DEGLI STUDI DI SALERNO

Maestría en Ciencia Política

\title{
ESTUDIOS HISTÓRICOS
}

\section{LA FLUIDEZ DE LA POBLACIÓN Y LOS NACIMIENTOS ILEGÍTIMOS EN CALDAS Y NORTE DEL VALLE: (1905-1932)} THE FLUCTUATION OF THE POPULATION AND THE ILLEGITIMATE BIRTHS IN CALDAS AND

THE NORTH OF VALLE: (1905-1932)

Estela María Vélez Mejía

pp. 02-17

Vol. 2 Núm. 2, Julio-Diciembre de 2018

Pereira, Colombia 


\section{LA FLUIDEZ DE LA POBLACIÓN Y LOS NACIMIENTOS ILEGÍTIMOS EN CALDAS Y NORTE DEL VALLE: (1905-1932)* THE FLUCTUATION OF THE POPULATION AND THE ILLEGITIMATE BIRTHS IN CALDAS AND THE NORTH OF VALLE: (1905-1932)}

Estela María Vélez Mejía** estelamvelezm@gmail.com

ORCID: http://orcid.org/0000-0002-7666-6875

\begin{aligned} & \hline Recibido: 09 de mayo de 2018. \\ & Revisado: 20 de agosto de 2018. \\ & Aceptado: 21 de septiembre de 2018. \\ & Publicado: 23 de noviembre de 2018. \\ & \hline\end{aligned}

\section{Resumen}

Este documento expone un resumen acerca de una investigación de la ilegitimidad en los nacimientos en cuatro lugares de la región: Aguadas, Santa Rosa de Cabal, Pereira y Cartago. El trabajo se elaboró a partir de fuentes documentales como los archivos parroquiales y los anuarios estadísticos del período comprendido entre 1905 y 1932. Los datos que se extrajeron para elaborar las tablas, nos condujeron a algunas conclusiones acerca de la ilegitimidad, la sociedad y el tipo de familia de este período. Este trabajo es un aporte inicial para la historia social y de la familia en la región.

Palabras clave: ilegitimidad, registros parroquiales, anuarios estadísticos, historia social.

\begin{abstract}
This paper intends to expose a brief about a research on the illegitimacy of births, in four different towns of the region: Aguadas, Santa Rosa de Cabal, Pereira and Cartago. The work has been elaborated from documents as Parrish registries and Statistic Yearbooks, between the years 1905 and 1932. The data extraction done and organized in order to elaborate the tables, lead us to some conclusions about illegitimacy, society and types of family in this period. This work is an initial contribution to the social and family history of the region.
\end{abstract}

Keywords: Illegitimacy, Parrish registries, statistic yearbooks, social history.

\footnotetext{
* El presente artículo respeta las directrices y normas dispuestas en la Declaración de Ética de Publicación de Ciencia Nueva, Revista de Historia y Política. Esta declaración puede consultarse en la página web de la revista: revistas.utp.edu.co/index.php/historia

** Licenciada en Filosofía y candidata a Magíster en Historia de la Universidad Tecnológica de Pereira. Docente de Educación Básica en el área de Ciencias Sociales.
} 
U no de los períodos más complejos e inexplorados de nuestra historia en Colombia es el inicio del siglo XX. Especialmente, la historia social y de la familia y la ilegitimidad en los nacimientos. El volumen de los archivos es bastante grande, por lo que hay gran dificultad para trabajar y organizar sistemáticamente la información de anuarios estadísticos y registros parroquiales que nos permitan estudiar este aspecto.

El período abordado en este trabajo está comprendido entre 1905 y 1932, años en los que el país comenzó a crecer en vías y transporte. Las líneas del ferrocarril de Caldas y el Pacífico interconectaron, poco a poco, lo que hoy es el Norte del Valle, Risaralda y Caldas.

Si bien, el tema del ferrocarril o la economía no es el centro de la discusión en nuestra exposición, es indudable que este medio de transporte significó un movimiento económico, político y, más aún, social. Pues las personas que participaron en la construcción y desarrollo de ese ferrocarril, pertenecieron a familias que, en ocasiones, se desintegraron temporalmente, debido a la cantidad de tiempo que los hombres debían pasar lejos del hogar. Así pues, una de las posibilidades que se plantean, dado el número de parejas con uniones informales e hijos ilegítimos en ciertos lugares de nuestra geografía, puede responder al desplazamiento interregional.

\section{Ilegitimidad}

En Colombia, las uniones ilegítimas de pareja comenzaron desde la llegada de los españoles; podría decirse que el amancebamiento constituyó una respuesta al desbalance demográfico, como lo dice Rodríguez:

Desde el comienzo, los conquistadores llevados de la pasión y la necesidad, "se echaron" con las indias, las más de las veces forzándolas y otras seduciéndolas. Situación a la que contribuían los caciques que daban mujeres a los tenientes como muestra de lealtad o en pacto de paz. Estas relaciones, debe imaginarse, eran muy pasajeras en un principio, pero en la medida en que los enfrentamientos entre españoles e indígenas se atenuaron, estas uniones se fueron volviendo estables y duraderas ${ }^{1}$.

Si bien, los europeos podían llegar a amar y vivir largo tiempo con las indias, estas, sin embargo, no eran consideradas aptas para el matrimonio y en muy contadas ocasiones se legitimó el concubinato entre las parejas de español/indígena.

Y es que los europeos fundaban las ciudades, permanecían algún tiempo allí con las mujeres que les habían "asignado", engendraban a sus hijos y luego continuaban sus campañas en otros territorios. Esos niños y niñas comenzaron a engrosar la franja de mestizos con un solo apellido en las diferentes regiones.

Al pasar un siglo, en los sitios geográficos donde había mayor cantidad de población de negros y mulatos, los españoles se unían a las mujeres afro de la misma manera que lo habían hecho con las indígenas -formando la franja de mulatos-. Mientras en los campos, los indígenas y los esclavos se unían entre ellos procreando mulatos, pese a la prohibición de la Corona española.

Ahora bien, la Iglesia exhortaba a los que se encontraban en tales situaciones a ponerse en "estado de gracia". Aunque el interés institucional pareció centrarse en salvar las almas españolas e indígenas, mostrando poco interés por los mestizos, mulatos o zambos. Estos grupos, en raras ocasiones, celebraban uniones matrimoniales, aunque las mujeres sí

\footnotetext{
${ }^{1}$ Pablo Rodríguez, "La familia en Colombia”, en La familia en Iberoamérica 1550 - 1980 (Bogotá: Universidad Externado de Colombia, 2004), 257-258.
} 
acudían a las pilas bautismales para registrar a sus hijos. Guiomar Dueñas ${ }^{2}$ resalta que los costos de la ceremonia religiosa y la celebración social, estaban fuera del alcance de casi todas las personas de los sectores populares quienes desempeñaban oficios variados como artesanos, jornaleros, sirvientas, chicheras, etc. Por esta razón, a finales del siglo XVIII, el matrimonio fue un símbolo de separación entre nobles y plebeyos en la sociedad santafereña ${ }^{3}$, dadas las rudas reglas que la sociedad colonial tenía frente a las uniones de personas con diferentes "razas" y/o condiciones económicas. Así pues, la ilegitimidad en las uniones tuvo una influencia muy grande en el reconocimiento de los hijos e hijas en los enlaces que no estaban considerados como legales.

En el siglo siguiente, las consecuencias del proceso de independencia del que se beneficiaron unos cuantos grupos de familias se visibilizaron en el desbalance social, incluso, en los pensamientos políticos que se desarrollaron en las décadas siguientes. Dada la polarización del país, hubo varias propuestas constitucionales - unas de corte federalista y otras de inclinaciones centralistas- que presentaban visiones opuestas de la sociedad, la educación y el matrimonio. Por ejemplo, para los federalistas, el matrimonio civil debía ser legal y con este los frutos de tal unión; mientras que los centralistas consideraban que solo la iglesia debía otorgar tales derechos. De este modo, el número aproximado en medio del debate político y social fue de hasta diez constituciones.

La Regeneración, en cabeza de Rafael Núñez y José Antonio Caro, propuso a fines del siglo XIX un proyecto político que pensaba recobrar las ideas del centralismo y los valores católicos -entendidos como valores morales- ${ }^{4}$, dado que la Iglesia se consideró, la principal entidad -al lado del Ejército- que poseía una autentica estructura de funcionamiento y tenía toda la influencia para mantener los valores que el Estado necesitaba en ese momento. Políticamente, no solo se derrotaban los valores federalistas, además La Regeneración fundamentó el modelo de Estado en la constitución de 1886 y también las leyes, códigos y reglamentaciones de esta ${ }^{5}$.

Precisamente la Ley 153 de 1887, encargada de estructurar, reglamentar y reformar códigos nacionales, dice acerca de la condición de legitimidad e ilegitimidad de los infantes que:

Los hijos nacidos fuera de matrimonio, no siendo de dañado ayuntamiento ${ }^{6}$, podrán ser reconocidos por sus padres o por uno de ellos, y tendrán la calidad legal de hijos naturales

\footnotetext{
${ }^{2}$ Dueñas Vargas, “Adulterios, amancebamientos y abandono: la fluidez de la vida familiar santafereña, 17501810", Anuario Colombiano de Historia Social y de la cultura 23 (1996): 33-48

${ }^{3}$ Dueñas Vargas, "Adulterios, amancebamientos y abandono: la fluidez de la vida familiar santafereña, 1750$1810 ", 33-48$.

${ }^{4}$ La Ley 153 de 1887 dice en su artículo 13: "La costumbre, siendo general y conforme con la moral cristiana, constituye derecho, a falta de legislación positiva". Y la Corte Constitucional declaró exequible este artículo mediante la Sentencia C-224 de 1994, en el entendido que la expresión "moral cristiana" significa "moral general" o "moral social", como se indica en la parte motiva de la sentencia. Ley 153 de 1887, disponible en http://www.alcaldiabogota.gov.co/sisjur/normas/Norma1.jsp?i=15805.

${ }^{5}$ Véase: Jorge Orlando Melo, Nueva Historia de Colombia Volumen III (Bogotá: Editorial Planeta, 1989).

${ }^{6}$ Esta expresión se deriva del cuerpo de Leyes del Rey Alfonso X, en esta, la expresión "hijos de dañado ayuntamiento", se refiere a aquellos que provienen de uniones sexuales consideradas delictivas: adulterio, incesto o sacrilegio. Juan Flórez de Ocariz en el Tomo II cita este mismo concepto al hacer sus aclaraciones acerca de los hijos legítimos.
} 
respecto del padre o de la madre que los haya reconocido ${ }^{7}$. [...] El reconocimiento es un acto libre y voluntario del padre o de la madre que reconoce ${ }^{8}$.

Sin duda, la ley pretendía evitar la orfandad de los niños, y es que la calidad de vida de estos ha sido y es definida por el cuidado que le sea brindado por al menos uno de los padres. El abandono, casi siempre, era condenar a muerte o a trabajos forzados durante la infancia y adolescencia a los niños y niñas. En medio del azar o el desespero, algunas madres dejaban a sus criaturas en caminos o puentes donde la mayoría sucumbía por el frío o devorada por algún animal. Asimismo, los bautizados como destino, en caso de ser niñas era el convento y si eran varones era las casas de familias acaudaladas para ocuparse de traer agua, leña y de oficios varios ${ }^{9}$. Entonces, el abandono condenaba a las criaturas a un destino nefasto o a trabajos forzados en alguna residencia extraña.

Tal vez, con el fin de prevenir las complicaciones a las madres solteras que no querían entrar en dilemas con quienes negaron a sus hijos, encontramos en el artículo 54 de la Ley 153 de 1887 que quien reconoce a la criatura no está obligado a decir quién es la otra persona que lo engendró; lo que implica que se libera de toda responsabilidad a quien decide no hacerse cargo de su criatura, pero abre la puerta a quien lo bautiza y reconoce para hacerse cargo de él.

Ahora bien, las clases de hijos ilegítimos también están contempladas en esta legislación:

Se llaman naturales los hijos habidos fuera de matrimonio de personas que podían casarse entre sí al tiempo de la concepción, cuyos hijos han obtenido el reconocimiento de su padre o madre, o ambos, otorgado por escritura pública o en testamento [...] Se llaman de dañado y punible ayuntamiento los adulterinos y los incestuosos. Es adulterino el concebido en adulterio; esto es, entre dos personas de las cuales una, a lo menos, estaba casada al tiempo de la concepción con otra [...] Es incestuoso para dichos efectos, el hijo habido entre dos personas que no pueden casarse por las relaciones de parentesco natural o civil, y por las cuales sería nulo el matrimonio ${ }^{10}$.

Ser ilegítimo constituía una marca que impedía avanzar socialmente en una sociedad que tradicionalmente hacía honor al nacimiento legítimo, en la que el tipo de inscripción en un registro bautismal o censal constituía un mecanismo de inclusión o exclusión. Como lo dice Rodríguez:

El mal nacimiento era un oprobio inexpiable y, para el bastardo, una tara indeleble. Aun en los sectores populares, más habituados a la cuestión de los hijos naturales [...] Seguramente en ciertas circunstancias la ilegitimidad debía ser sufrida como una fatalidad. No obstante, una gran capacidad de silenciar y olvidar enseña su voluntad para sobrellevar las altísimas tasas de nacimientos ilegítimos advertidos por los sacerdotes. Situaciones que recibían complicidad y tolerancia o recriminación cuando eran presentados los frutos de estas uniones en las pilas bautismales ${ }^{11}$.

\footnotetext{
${ }^{7}$ Ley 153 de 1887 , artículo 54.

${ }^{8}$ Ley 153 de 1887 , artículo 55.

${ }^{9}$ Pablo Rodríguez, "La familia en Colombia", 267.

${ }^{10}$ Código Civil del 23 de mayo de 1873, artículo 52.

${ }^{11}$ Pablo Rodríguez, Seducción, amancebamiento y abandono en la Colonia (Bogotá: Fundación Simón y Lola Guberek, 1991), 46.
} 
Si bien es cierto que durante la Colonia en los registros bautismales, la condición ilegítima constituía entre $40 \%$ y $60 \%$ de los bautizados, la sociedad continuaba considerando que este era un problema exclusivo de clases bajas. Así pues, la calidad de ilegítimo en la vida adulta implicaba que no se iba a ingresar a colegios de confesión religiosa ni tampoco a las universidades o cargos de gobierno, menos aún a las asociaciones de gente noble o descendiente de aquellos.

La Iglesia católica se apoyó en el triunfo de la Regeneración, expresado en la constitución de 1886 y los códigos posteriores. Así, cuando se firmó el Concordato de 1887 desapareció la posibilidad legal del matrimonio civil, y a través de la Ley 30 de 1888 se permitió que "el matrimonio católico, anulase el matrimonio civil celebrado antes por los contrayentes con otra persona" 12 . Pero la consecuencia era que el hombre debía mantener a la primera mujer y a los hijos habidos en ella ${ }^{13}$.

Sin duda, la Ley 153 de 1887 contiene todas las figuras legales que fueron adaptadas por los centralistas, la Iglesia y tradicionalistas para defender sus valores morales respecto de la familia y la legitimidad de las uniones y de los hijos. Asimismo, las leyes derivadas del concordato con la Iglesia favorecen la idea de familia mantenida hasta ese momento, aunque en algunos casos, en aparente detrimento con las mujeres que hubiesen contraído nupcias en ritos diferentes al católico.

\section{El siglo XX}

La inequidad y la sujeción a la Iglesia católica fueron características determinantes en la conceptualización y materialización -no solo a través de la ley, sino también en la vida cotidiana- de conceptos como familia e ilegítimo; así como el papel de las mujeres en la sociedad, en este caso, nos referimos tanto a las madres solteras, como a las mujeres con uniones legales o bendecidas por la Iglesia ${ }^{14}$.

$\mathrm{Si}$ bien las leyes se mantuvieron intactas al inicio del siglo $\mathrm{XX}$, hubo muchas figuras femeninas como María Cano y Soledad Acosta ${ }^{15}$ que empezaron a mostrar públicamente otras facetas de la mujer en Colombia. De la misma manera, personajes masculinos de la vida pública antioqueña como Carlos E. Restrepo, Tomás Carrasquilla, Luis López de Mesa, Baldomero Sanín Cano, entre otros, abogaron a su tiempo por mejorar las condiciones de las mujeres en cuanto a la educación, el trabajo y su reconocimiento en la sociedad. Así pues, en 1922, la convención del Partido Liberal reunida en Ibagué, aprobó un programa de acción que contribuyera a mejorar las condiciones de las mujeres casadas y les asegurara un puesto en la vida social. En 1928, el representante Absalón Fernández presentó un proyecto de ley para que a las mujeres se les autorizara desempeñar cargos públicos, poder comparecer en juicios por sí mismas y administrar sus bienes a pesar de estar $\operatorname{casadas}^{16}$.

\footnotetext{
${ }^{12}$ Mauricio Beltrán, “Una visión sociológica del derecho de familia en Colombia. Radicalismo-1945”, Estudios Socio-Jurídicos. (2008).

${ }^{13}$ Magdala Velásquez Toro, “Aspectos de la condición jurídica de las mujeres”, en Las mujeres en la historia de Colombia (Bogotá: Editorial Presencia, 1995), 173-187. Artículo 36, ley 1888.

${ }^{14}$ Recordemos que solo estas eran legales, como ya citamos.

${ }^{15}$ Ya en el siglo previo hubo varias heroínas de la Independencia, como Antonia Santos y Policarpa Salavarrieta. Incluso Manuela Sáenz, quien ayudó a Bolívar a escapar cuando fueron a asesinarlo, se consideró una heroína.

16 Magdala Velásquez Toro, "La República Liberal y la lucha por los derechos políticos y civiles de las mujeres", en Las mujeres en la historia de Colombia (Bogotá: Editorial Presencia, 1995), 183- 209.
} 
Después de la hegemonía conservadora, en el período de la República Liberal, durante la presidencia de Enrique Olaya Herrera, el ministro de gobierno Carlos E. Restrepo presentó una ley en la que se pretendía otorgar autonomía patrimonial a las mujeres casadas; este proyecto no pasó y el presidente Olaya debió contratar a otro abogado, Luis Felipe Latorre, para realizar un estudio de las reformas requeridas, de manera que se otorgaran derechos civiles a las mujeres ${ }^{17}$, puesto que no podían administrar por sí mismas sus bienes y necesitaban siempre la firma de su esposo -en caso de ser casadas-, de un hermano o pariente hombre. Aún las madres solteras, dependían de un pariente masculino para hacer legítima una herencia, compra, venta, etc. ${ }^{18}$. Finalmente, luego de muchos debates y oposiciones por parte de los sectores conservadores, se aprobó y se convirtió en La Ley 28 de 1932.

Bajo el gobierno de Alfonso López Pumarejo, hubo una comisión que se interesó en la reforma constitucional y su interés fue la protección de la familia, la maternidad, la igualdad jurídica de derechos de hijos legítimos e ilegítimos, la libre investigación de la paternidad, el divorcio, etc. Estas reformas aparecen en la Ley 45 de 1936. Bajo el gobierno de Alfonso López Pumarejo, se realizaron algunos cambios sobre la calidad de ilegítimo que pasa a ser hijo natural:

[...] La Contraloría General de la Nación demuestra que el total de hijos ilegítimos en el país era casi del 50\%, y en algunos departamentos como Bolívar, Magdalena, Intendencia del Chocó, Caquetá, estaba alrededor del 75\% [...] el autor infiere que el número de hijos ilegítimos era superior de los que la Contraloría demostraba. Concluye el autor afirmando que para quienes respaldaron la ley en el Congreso la propuesta, al contrario de lo que pensaban sus oponentes, estuvo en armonía con la "moral y las buenas costumbres"

En general, esta ley nueva otorgaba una equidad en los derechos de las madres, pues se les daba la posibilidad de imputar el reconocimiento hecho por el padre sin su consentimiento $^{20}$. En la misma media, se les otorgó patria potestad completa sobre su hijo natural, o al padre del hijo con una orden judicial en caso de que la madre no esté y que el padre no esté casado ${ }^{21}$. Esta misma ley presentó la posibilidad de los derechos de herencia, tanto a legítimos como a hijos naturales ${ }^{22}$.

La situación en el país debió ser caótica a este respecto. Los legisladores se sintieron motivados a reconocer la realidad social en ese aspecto particular, pues las estadísticas mostraban que no solo las familias bendecidas por la Iglesia, como lo pensaron y ordenaron en la Constitución de 1886, engendraban hijos e hijas; también lo hacían las viudas, los

\footnotetext{
17 Velásquez Toro, “La República Liberal y la lucha por los derechos políticos y civiles de las mujeres”, 191.

${ }^{18}$ Por ejemplo, en Cartago en el año 1918, una mujer que se siente al borde de la muerte, suplica al juez para poder nombrar un albacea para su hijo, dado que alguien donó unos dineros y un bien raíz para el menor, ella como mujer no puede disponer de ellos; se hace visible en los documentos que la madre por sí misma no puede negociar, comprar, vender, heredar a su hijo, sin un trámite judicial; por ello invoca el tutor. La madre fallece a los pocos días. Este proceso dura más de un año, y el tutor reitera varias veces, la solicitud para que se le entregue el bien y el dinero al muchacho. Archivo Histórico de Cartago Valle del Cauca. Archivo de Procesos Civiles, 1918 .

${ }^{19}$ Gustavo A. Valbuena, Derechos de los hijos naturales (Bogotá: Talleres Mundo al Día, 1936). Beltrán, “Una visión sociológica del derecho de familia en Colombia. Radicalismo-1945”, 150.

${ }^{20}$ Ley 45 de 1936, artículo 9, disponible en http://www.suin-juriscol.gov.co.

${ }^{21}$ Ley 45 de 1936, artículo 14.

${ }^{22}$ Ley 45 de 1936, artículo 22. Modifica al 1050 del Código Civil.
} 
solteros y solteras, los hombres y mujeres casados por fuera de su matrimonio, los divorciados, etc.

La legislación inicial -la canónica y la estatal- plasmada en la legislación de 1886, trabajó con un principio excluyente frente a los ilegítimos; así pues, la ley en 1936, intentó extenderse un poco más para abarcar la realidad que el país estaba presentando. Durante los años treinta y cuarenta, las crisis económicas y políticas, a nivel mundial, presentaron la posibilidad de tener otras visiones acerca de lo que debía ser la ley para el país y para los hijos de las distintas uniones posibles. Durante la República Liberal, Olaya Herrera otorgó derechos básicos las mujeres, mientras Alfonso López Pumarejo empezó a reglamentar los de los niños sin padre. Hasta aquí nos referimos a los aspectos políticos. A continuación, se expondrán los resultados de las estadísticas parroquiales y de anuarios estadísticos investigadas para el siglo $\mathrm{XX}$.

\section{Aguadas, Cartago, Santa Rosa y Pereira}

A principios de siglo, los departamentos se dividían en provincias y estas a su vez en distritos municipales. El Anuario Estadístico de 1905 menciona que los departamentos de Caldas -con 4 provincias- y Cauca - con 13 provincias-, contaban con 19 y 71 municipios respectivamente ${ }^{23}$.

En este momento se registraba una población reducida: Aguadas, que pertenece a la provincia de Aránzazu, tenía 11294 habitantes; Santa Rosa contaba con 3872, y Pereira con 633, ambas pertenecían a la provincia de Robledo. Mientras en Cartago habitaban 7696 personas, la provincia de la que hacía parte era la del Quindío (Figura 1). Los dos primeros hacían parte del departamento de Caldas -que contaba en total con 91365 habitantes y Cartago formaba parte del departamento del Cauca-con 259121 pobladores ${ }^{24}$. Es importante anotar que este censo cuenta con una población muy baja, dado que habían pasado solo dos años desde el fin de la guerra civil. Para este momento no contamos con datos acerca de sexo o ilegitimidad, los datos del anuario proporcionan únicamente cantidad de habitantes.

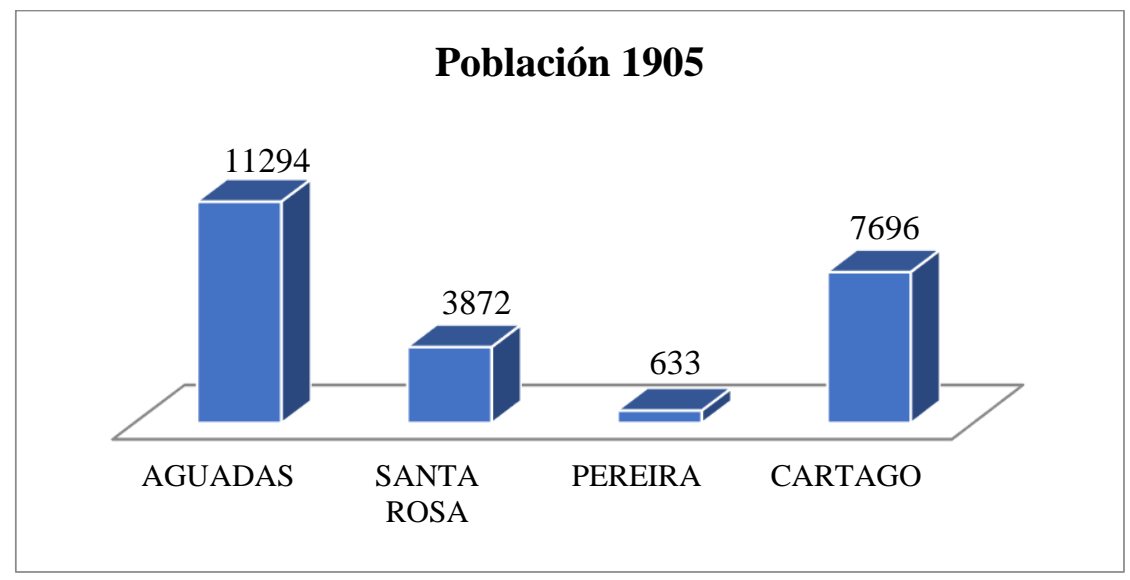

Figura 1.

Población 1905.

Fuente: Estadística de la República 1905. http://biblioteca.dane.gov.co

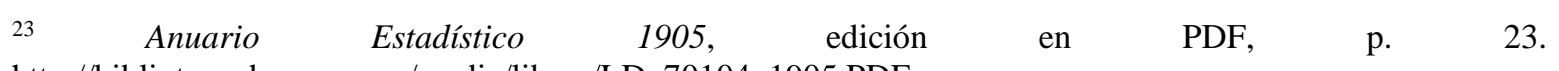
http://biblioteca.dane.gov.co/media/libros/LD 70104 1905.PDF.

${ }^{24}$ Anuario Estadístico 1905, edición en PDF, p. 43. 
Aguadas y Cartago tenían la mayor cantidad de pobladores, esto podría indicar que se convertirían en grandes ciudades; no obstante, esto no fue lo que sucedió. Ahora bien, el departamento de Caldas fue refrendado en la administración de Reyes (1905), mientras en el caso del Valle del Cauca, sus políticos, agotados por la forma en la cual la gobernación de Popayán administraba los recursos, comenzaron a intervenir en favor de separarse de la gobernación del Cauca. Después de muchos ires y venires, en 1910 el departamento quedó conformado por los territorios y jurisdicciones de Cartago, Buga y Santiago de Cali.

Ahora bien, las líneas del ferrocarril habían empezado a construirse, los hombres y mujeres se trasladan de sus lugares de vivienda habituales, la región comenzaba a transformarse, en siete años el panorama era diferente (Figura 2).

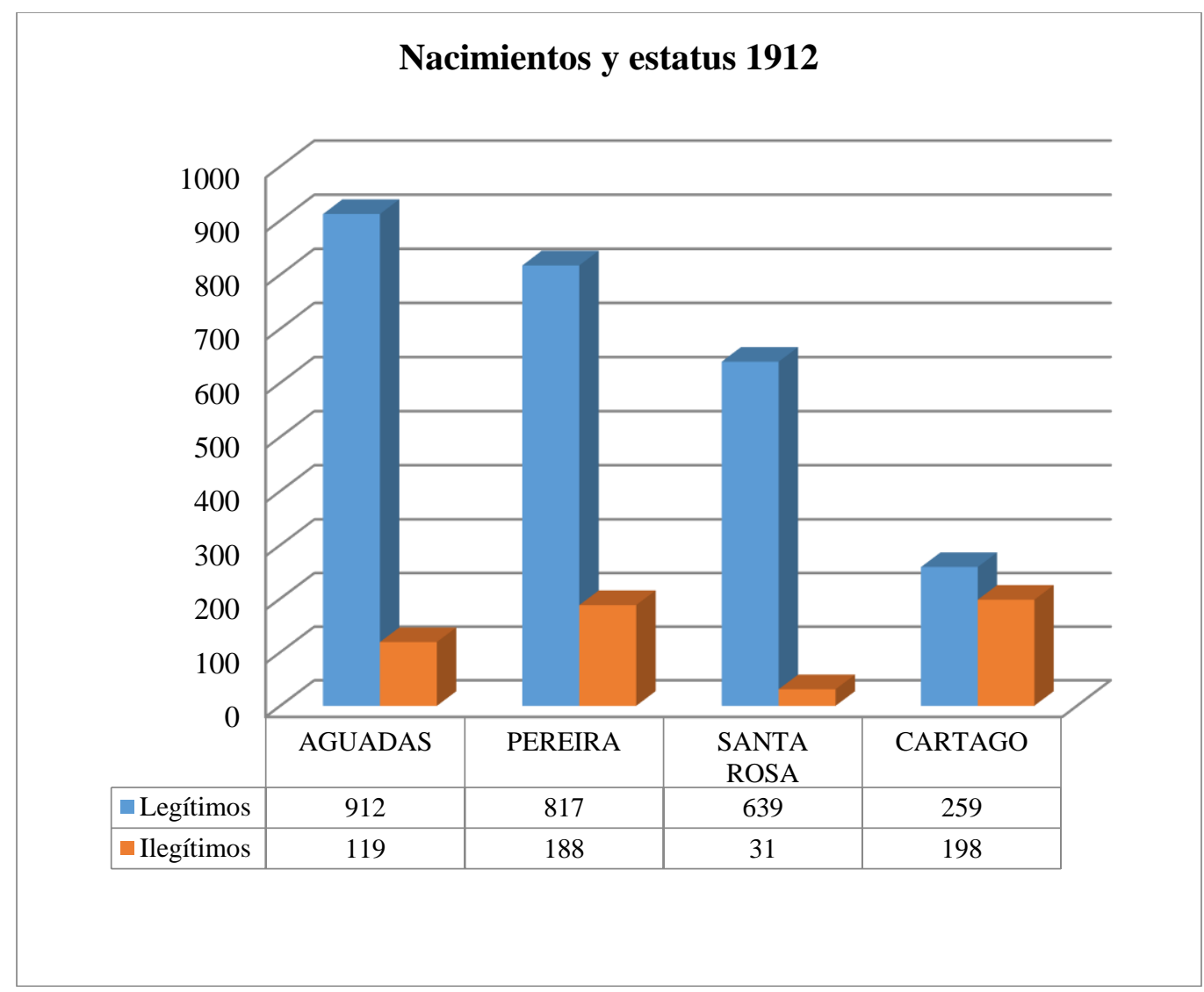

Figura 2.

Nacimientos y estatus 1912.

Fuente: Censo General de la República de Colombia, 1912, edición en PDF, p. 148 y 207. http://biblioteca.dane.gov.co/media/libros/LD_771_1912.PDF. Departamento de Caldas y departamento del Valle.

Este anuario estadístico nos presenta un crecimiento de los nacimientos en Pereira y un descenso en los nacimientos en Cartago; al respecto de la ilegitimidad de nacimientos, podemos observar que es mayor en ambos municipios, al respecto de los otros dos lugares.

Ahora bien, al hablar de la Colonia, los mencionados trabajos de Rodríguez y Dueñas proponen, desde la revisión de archivos judiciales, que los delitos de amancebamiento y adulterio, penalizados también por las leyes de ese momento, son la razón de algunos casos de ilegitimidad. 
La constitución de 1886 -vigente en este período- continuó castigando este tipo de conductas. De modo que en las cárceles de la República hubo detenidos por diversos crímenes. En cuanto al amancebamiento, el anuario registra 62 detenidos en Caldas y 188 en el Valle del Cauca. El total de la República es de 589, lo que significa que entre los dos departamentos de nuestro interés, tienen un 42,4 \% del total de la nación; una cifra bastante significativa y que nos da una pista más para explicar las cifras de ilegitimidad, pues el adulterio, como ya citamos, llevaba al abandono del hogar propio -casi siempre a los hombres, aunque hubo casos de mujeres acusadas también por ello-y los hijos -reconocidos o no- para formar nuevas uniones en otros lugares con otra pareja.

Ahora bien, la tabla presentada en el anuario ${ }^{25}$ no permite saber el sexo de los detenidos para determinar cuántas mujeres estaban acusadas o detenidas por este delito, finalmente, en un lugar con baja sanción social las posibilidades podían ser más favorables. Entre 1912 y 1918, el número de habitantes en los 4 municipios mencionados aumentó.

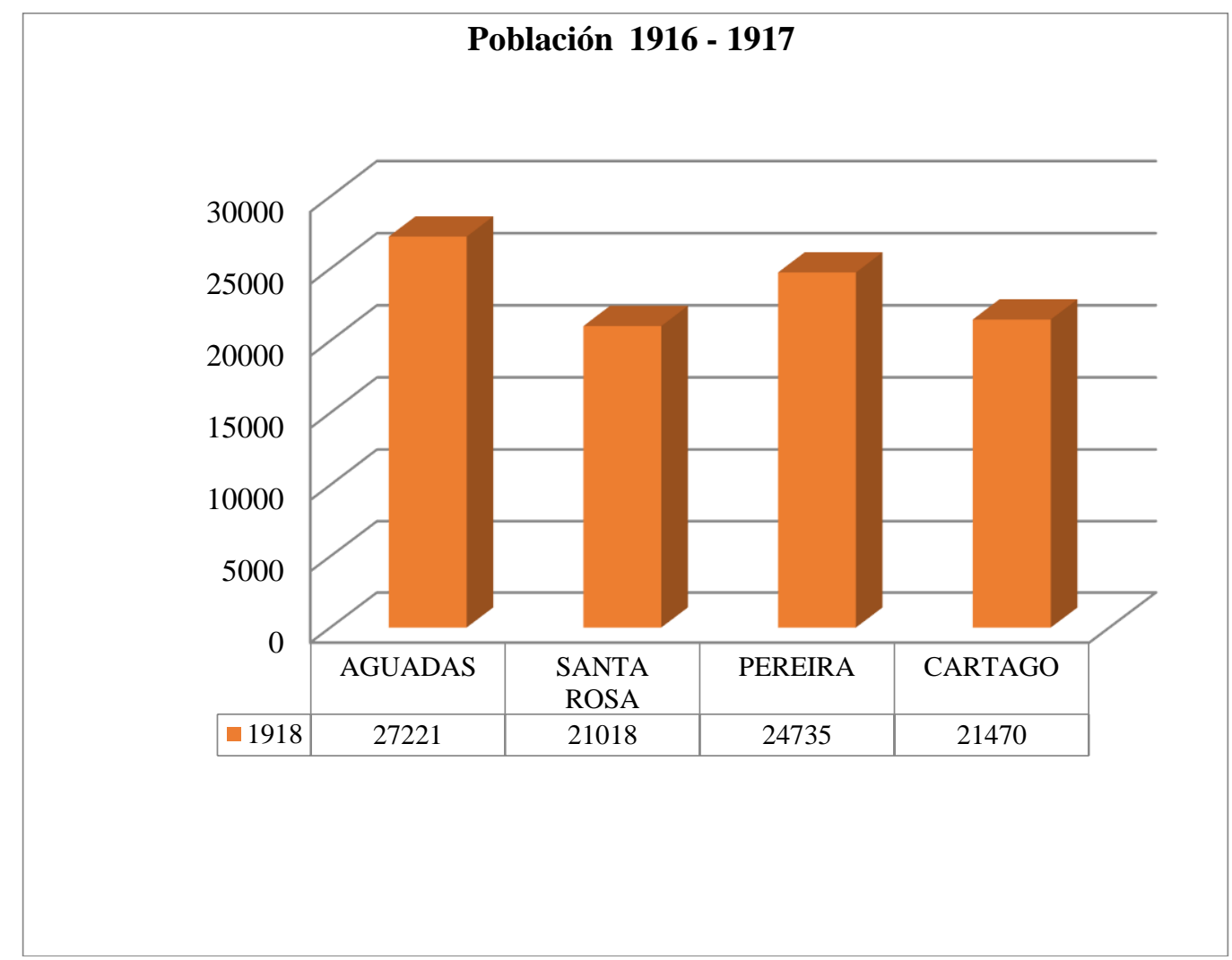

Figura 3.

Población 1919-1917.

Fuente: Anuario Estadístico (1916 - 1917), edición en PDF. http://biblioteca.dane.gov.co/media/libros/LD 70104_1916_1917.PDF.

Al respecto de la población, el municipio de Pereira fue el de mayor crecimiento en estos 6 años, con más de 6000 habitantes. Aguadas, fue el que menos creció, con solo 1000 habitantes más. La Figura 4 muestra la ilegitimidad a través de los registros parroquiales ${ }^{26}$ de 1918.

${ }^{25}$ Censo General de la República de Colombia, edición en PDF, p. 455.

${ }^{26}$ Desafortunadamente, no tuvimos la posibilidad de revisar los registros parroquiales de Pereira. 


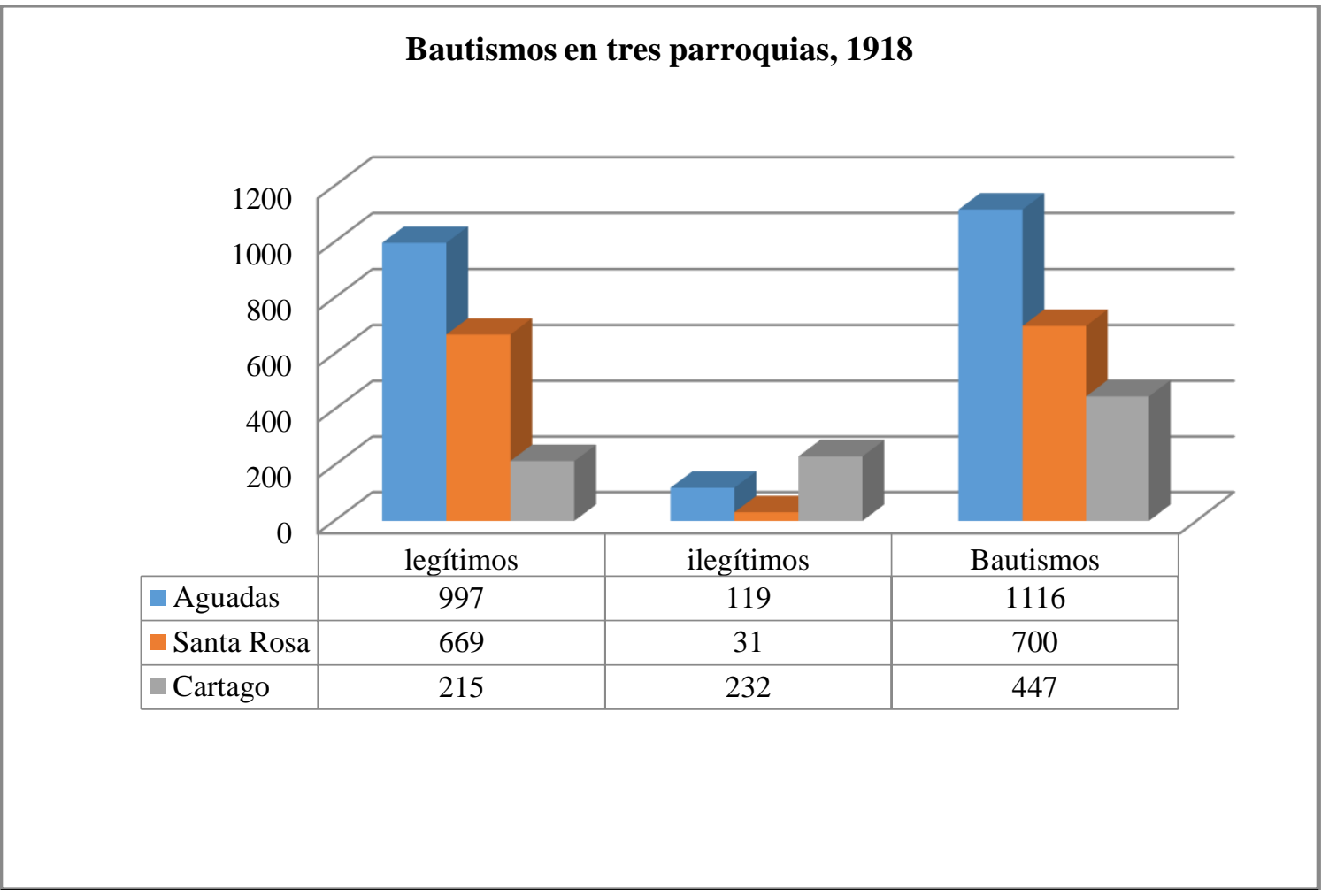

\section{Figura 4.}

Bautismos en tres parroquias, 1918.

Fuente: www.familysearch.org para Aguadas, Volumen 38 Parroquia Inmaculada Concepción, 1918. Para Cartago, Libro 32 Parroquia de San Jorge 1918. Para Santa Rosa, volumen 24 Parroquia de Nuestra Señora de las Victorias.

Esta tabla nos presenta la posibilidad de examinar lo que significa la ilegitimidad en estos tres municipios; en Cartago, el porcentaje de población es más bajo, pero el de ilegitimidad es mayor, con respecto a las otras localidades ${ }^{27}$.

El cuadro de población (Figura 3) frente al de nacimientos (Figura 5), nos permite comprobar que el municipio con mayor crecimiento, dada la cifra de habitantes y la de cantidad de nacimientos, parece ser Aguadas.

Dada la ausencia de datos parroquiales de Pereira, debemos tener en cuenta la dinámica de crecimiento de población que se dio en ese municipio en 1905; de este modo, podemos pensar que el valor de ilegitimidad para 1918, pudo ser similar, así como el de nacimientos, es decir, es posible que en los nacidos y bautizados, el valor se conserve en un $23 \%$ de ilegitimidad.

\footnotetext{
${ }^{27}$ Es importante tener en cuenta que en Cartago solo existía una parroquia en este momento, la de San Jorge. Si bien había otros templos, este era el único autorizado para impartir los sacramentos.
} 


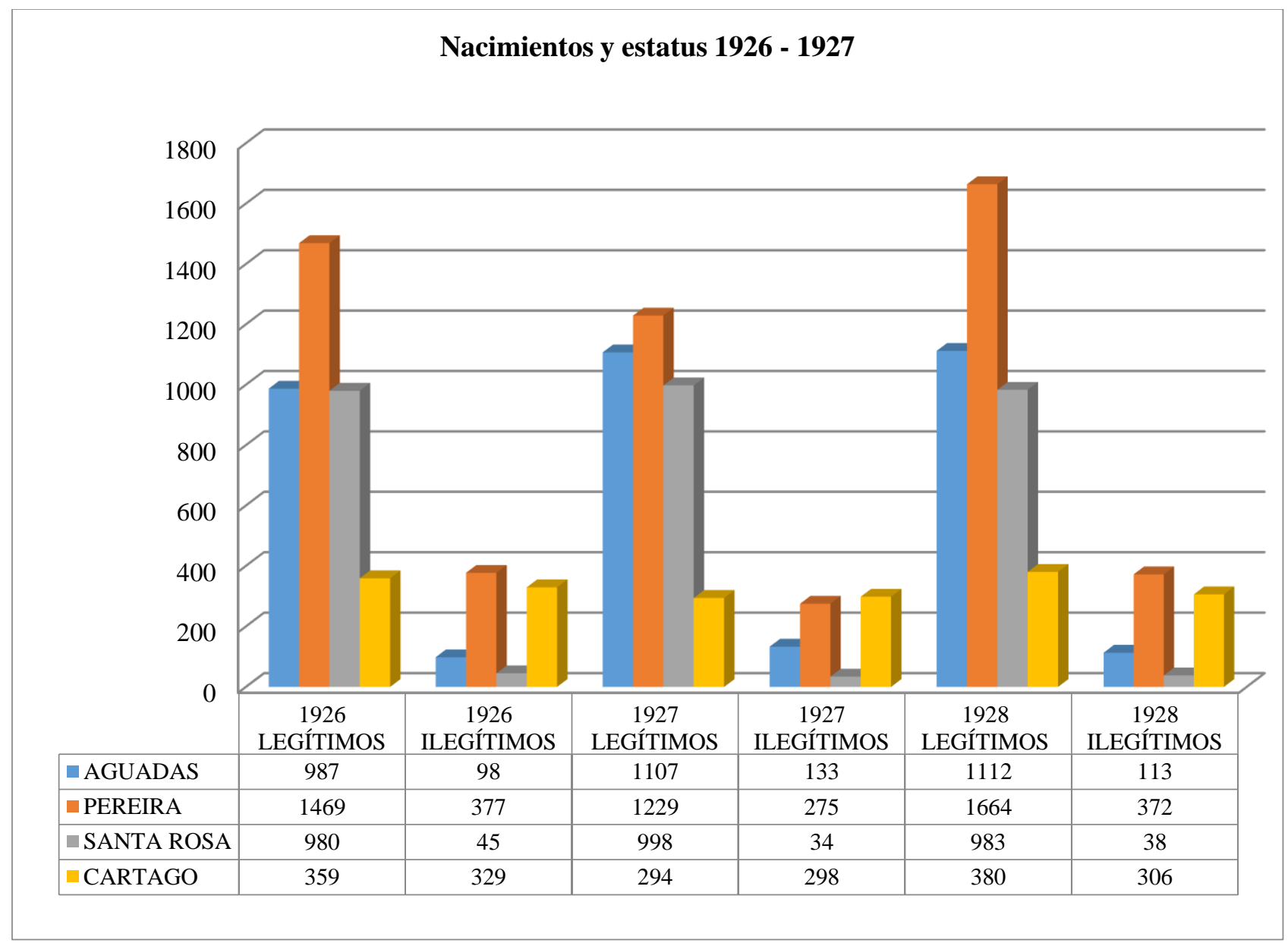

Figura 5.

Nacimientos y estatus $1926-1927$.

Fuente: Anuario General de Estadística 1928, edición en PDF. http://biblioteca.dane.gov.co/media/

En el curso de tres años, la ilegitimidad en Aguadas oscila entre el $9 \%$ y el $10 \%$, Pereira oscila entre el $20 \%$ y el $22 \%$; Santa Rosa presenta un porcentaje de entre 3,7 \% y $4,3 \%$; Cartago presenta 47,81\%, 50,33\%, 44,60\%.

Los nacimientos crecieron especialmente en la ciudad de Pereira, esto nos hace pensar en que la población comenzó a concentrarse en este lugar, así mismo la población de Santa Rosa.

Las variaciones en los porcentajes son mínimas a través de los años presentados en los anuarios. Al hacer el contraste entre archivos parroquiales en la Ciudad de Cartago, con las estadísticas presentadas en los libros parroquiales, los datos son muy similares. De modo que la información de ambos documentos parece fidedigna en relación con el estatus de nacimiento y población.

En los dos departamentos, cuando comenzó a funcionar el ferrocarril, se conectaron las líneas de Antioquia, Caldas y Pacífico; en la región estaba creciendo la vida y la economía fluían en cada rincón. La cantidad de nacidos y las concentraciones de población en distintos lugares nos plantean una incógnita que dejamos aquí como un trabajo pendiente para otra rama de la historia: ¿Por qué razón si todos estos lugares estaban conectados y tenían sus 
estaciones de ferrocarril y sus actividades económicas particulares, no se desarrollaron en medidas parecidas?

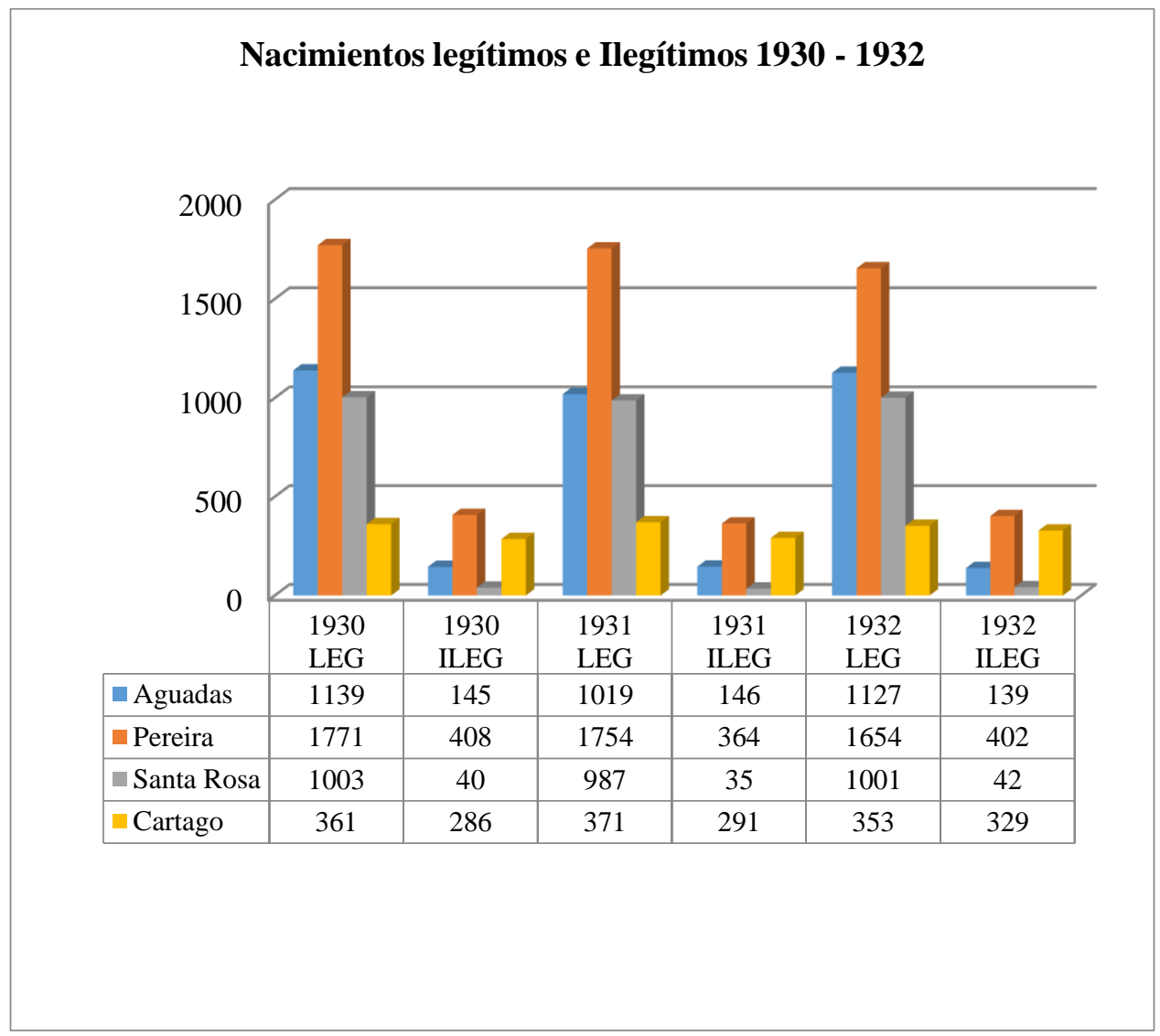

Figura 6.

Nacimientos legítimos e Ilegítimos 1930 - 1932.

Fuente: Anuario General de Estadística 1932, edición en PDF. http://biblioteca.dane.gov.co/media/ (Para Caldas págs. 37-40 y Valle págs. 66- 68).

Aguadas presenta en estos tres años un porcentaje de ilegitimidad de 11,29 \%, 12,75 $\%, 10,97 \%$; Pereira por su parte 18,72\%,17,18 \%, 19,55 \%; en Santa Rosa el porcentaje de ilegítimos en tres años es de 3,8 \%, 3,4 \%, $4 \%$; Cartago continua continúa con las cifras más altas de entre los cuatro municipios 44,20\%, 43,95\%, 48,24\%.

En esa época, la República Liberal comienza a proponer otras ideas y artículos constitucionales que tuvieron la intención de transformar las condiciones de las mujeres y sus hijos ilegítimos.

\section{Conclusiones}

Virginia Gutiérrez de Pineda nos expuso, en su texto de La Familia en Colombia, las características generales de lo que significa este concepto en nuestro país. Sin duda, somos una nación de regiones y la manera en la que vivimos -nacemos, nos unimos, nos separamos, morimos- en los distintos rincones de la geografía, se convierten en manifestaciones de esas diferencias, que no nos han separado aún. 
Ahora bien, dentro de la división expuesta por Gutiérrez de Pineda ${ }^{28}$ en los sesentas, la zona fluvio-minera del Pacífico y el litoral Caribe presentan una alta ilegitimidad que sobrepasa el $50 \%$ en filiación libre. Si bien, se refiere a la manera en la que se establece la pareja y los tipos de unión que se presentan en esta, la consecuencia de estas uniones libres inestables y esporádicas pueden dar como resultado la procreación del hijo con un solo apellido, dejados al cuidado de la madre mientras el padre realiza sus actividades de trabajo en otros territorios. Esta descripción está pensada para los sitios donde hay actividades mineras y donde los ríos son fundamentales para la subsistencia gracias a la pesca; en razón de ello, los hombres cambian el lugar de habitación con frecuencia.

La descripción realizada para el complejo cultural antioqueño, que incluye a Caldas, Antioquia, Tolima, Valle, con algunos enclaves en el Chocó. Según lo descrito por Gutiérrez, presenta una alta legitimidad tanto en uniones matrimoniales, como en lo referente a los hijos e hijas, sobre la ilegitimidad cita:

[...] esta ilegitimidad alcanza límites menores a la unidad y sólo asciende hasta el 10\% en las cifras más altas de la porción occidental, o al $15 \%$ en las vecindades del departamento del Chocó, ya bajo el influjo de la cultura litoral fluvio-minera ${ }^{29}$.

Ambas observaciones realizadas por la etnóloga, podrían aplicarse a los dos lugares examinados -los departamentos de Valle, representado por Cartago, y el de Caldas donde tenemos los tres restantes-. No obstante, el estudio que ella realizó tuvo lugar a mediados de los años 50 y 60, una época bastante posterior a la que expusimos en este escrito.

A través de los registros parroquiales y los anuarios estadísticos, Cartago parece más cerca del litoral fluvio-minero, descrito por la etnóloga, que al complejo antioqueño. Y es que ambos grupos de archivos -estadísticos y parroquiales- nos ofrecen una idea muy diferente, pues la ilegitimidad ronda en el municipio entre el 40 y $50 \%$ desde 1905 hasta 1932. Aquí, la familia presenta una configuración muy distinta a la que se pensaba... ¿Significará esto que, en este momento, la población tendría un componente afro que permaneció desde la Colonia? Es una de las preguntas que nos queda...

Estos datos encontrados al inicio de la investigación nos hicieron pensar en la región, y por esto se quiso introducir espacios que parecieran "fronterizos", "de paso hacia", y así se escogió a Aguadas y Santa Rosa dentro de la miríada de archivos existentes en la página. De manera fortuita se encontró, en los anuarios estadísticos de principios del siglo XX, información sobre el municipio de Pereira, incluido como referente comparativo.

Esta tarea investigativa dejó planteadas varias cuestiones: al respecto de la familia, por ejemplo, no cabe dentro de la generalidad descrita en la Antropología y la Etnología, pues, ¿cómo resultó posible que Cartago, que pertenecía al departamento del Cauca, rodeada de municipios tan religiosos y atentos con la norma constitucional y civil, resultara ser un lugar con tanta libertad para las mujeres y sus familias?

En este punto es pertinente aclarar que no se ve posible que el asunto de la ilegitimidad sea un fenómeno relacionado con la prostitución, ni en Pereira ni en Cartago. Coloquialmente algunos académicos explican el surgimiento o la fundación de pueblos con "el alcohol, el juego y la prostitución”. No obstante, una de las tareas que cada mujer tiene por sí misma es el conocimiento de los ritmos del propio cuerpo, con mayor razón puede pensarse que las

\footnotetext{
${ }^{28}$ Virginia Gutiérrez de Pineda, La familia en Colombia (Bogotá: CIS-FERES, 1962).

${ }^{29}$ Gutiérrez de Pineda, La familia en Colombia..., 30.
} 
mujeres dedicadas a este tipo de oficio, saben cuáles deben ser las estrategias y cuidados para evitar embarazarse, pues esto hace parte de su rutina.

Es por ello que se considera que el mito de la prostitución en Pereira y el Eje cafetero, se debe a una visión reduccionista de la situación; este fenómeno no se ha estudiado y pensado con calma en la historia dada la visión y metodología androcéntrica utilizada para pensar e interpretar el mundo que habitamos.

Dados los hallazgos en las cifras expuestas, una de las conclusiones planteadas puede ser que se trata de una forma de libertad, un triunfo de la idea y el manejo femenino de la familia, no necesariamente una rebeldía contra los parámetros católicos - de otro modo no se habrían registrado bautismos y en algunos casos tampoco matrimonios-, más bien una forma de asumir la vida, el papel de madre, de mujer, en una sociedad que hacía a un lado a todas las mujeres que tenían un solo apellido. Esta especie de solidaridad y tolerancia entre mujeres impidió que se presentara, como sucedió en Antioquia, la vigilancia a los movimientos y vidas de "los otros"; por esto cada quien conducía su vida a su antojo: mayor libertad de acción, pensamiento, formas de trabajo y elección de vida. 


\section{Bibliografía}

\section{Fuentes documentales}

Archivo Histórico de Cartago Valle del Cauca. Archivo de Procesos Civiles, 1900 - 1918.

\section{Bibliografía (consultada y/o citada)}

Bernard, Carmen y Serge Gruzinski. Los hijos del Apocalipsis: La familia en Mesoamérica y los Andes. Madrid: Alianza Editorial, 1988.

Beltrán-Cristancho, Mauricio. "Una visión sociológica del derecho de familia en Colombia. Radicalismo-1945”. Estudios Socio-Jurídicos 10, n. ${ }^{\circ} 2$ (2008), ISSN-e: 2145-4531.

Colmenares, Germán. La provincia de Tunja en el Nuevo Reino de Granada: 1539 - 1800. Bogotá: Universidad de los Andes, 1970.

Dueñas Vargas, Guiomar. “Adulterios, amancebamientos y abandono: la fluidez de la vida familiar santafereña, 1750-1810”. Anuario Colombiano de Historia Social y de la Cultura, n. ${ }^{\circ} 23$ (1996): 33-48. doi: 10.15446/achsc.

Dueñas Vargas, Guiomar. Los hijos del pecado. Ilegitimidad y vida familiar en la Santafé de Bogotá Colonial.1750-1810. Bogotá: Editorial Universidad Nacional, 1997.

Gutiérrez de Pineda, Virginia. La familia en Colombia. Bogotá: CIS-FERES, 1962.

Hobsbawm. E. J. Sobre la Historia. Barcelona: Crítica, 1997.

Jaramillo Uribe, Jaime. "La población indígena en el momento de la conquista". Anuario Colombiano de Historia Social y del Cultura, n. ${ }^{\circ} 2$ (1963): 239-293. doi: $10.15446 /$ achsc.

Melo, Jorge Orlando. Historia de Colombia: El establecimiento de la dominación española. Medellín: Editorial La Carreta, 1997.

. Nueva Historia de Colombia. Volumen III. Bogotá: Editorial Planeta, 1989.

O’Phelan Godoy Scarlett, Fanny Muñoz Cabrejo, Gabriel Ramón Joffré y Mónica Ricketts Sánchez. Familia y Vida Cotidiana en América Siglos XVIII - XX. Lima: Pontificia Universidad Católica del Perú, 2003.

Reyes, Carlos. "Semblanza de un patriota: el presidente del quinquenio", Revista Credencial Historia 175 (2004): 3-5.

Rodríguez, Pablo. Seducción, amancebamiento y abandono en la Colonia. Bogotá: Fundación Simón y Lola Guberek, 1991. 
- "Testamento y Vida familiar en el Nuevo Reino de Granada. Siglo XVIII”. Boletín Cultural y Bibliográfico 31, n. 37 (1994): 1-19.

. "La familia en Colombia". En La familia en Iberoamérica 1550 - 1980.

Coordinado por Pablo Rodríguez. Bogotá: Universidad Externado de Colombia, 2004.

Twinam, Ann. Vidas Públicas, secretos privados. Género, honor, sexualidad e ilegitimidad en la Hispanoamérica colonial. México: Fondo de Cultura Económica. 2009

Valbuena, Gustavo A. Derechos de los hijos naturales. Bogotá: Talleres Mundo al Día, 1936.

Vejarano, Fernán. Nacer, casarse y morir: un estudio de demografía histórica. Bogotá: Universidad Externado de Colombia, 1988.

Velásquez Toro, Magdala, Reyes Cárdenas, Catalina y Rodríguez J., Pablo. Las Mujeres en la Historia de Colombia. Bogotá: Editorial Presencia, 1995.

. "Aspectos de la condición jurídica de las mujeres". En Las mujeres en la historia de Colombia.173-187. Bogotá: Editorial Presencia, 1995.

- "La República Liberal y la lucha por los derechos políticos y civiles de las mujeres". En Las mujeres en la historia de Colombia.183-209. Bogotá: Editorial Presencia, 1995.

\section{Documentos de la red}

Anuario Estadístico 1905. Edición en $\quad$ PDF. http://biblioteca.dane.gov.co/media/libros/LD_70104_1905.PDF.

Anuario Estadístico $1916 \quad-\quad 1917 . \quad$ Edición en $\quad$ PDF. http://biblioteca.dane.gov.co/media/libros/LD_70104_1916_1917.PDF.

Anuario General de Estadística 1928. Edición en PDF. http://biblioteca.dane.gov.co/media/libros/LD_70104 1926.PDF.

Anuario General de Estadística 1932. Edición en PDF. http://biblioteca.dane.gov.co/media/libros/LD_70104 1932.PDF.

Censo General de la República de Colombia, 1912. Edición en PDF. http://biblioteca.dane.gov.co/media/libros/LD_771_1912.PDF.

Family Search. "Bautismos, vol. 38, 1922-1925". https://www.familysearch.org/ark:/61903/3:1:33S7-9T64-9F1?i=273\&wc=QZZSBG4\%3A1044036301\%2C1044574101\%2C1044606801\%2C1044625601\&cc=1726 $\underline{975}$

Family Search. “Libros 38, 39 y 40. 1918 -1928”. www.familysearch.org. 